DOI: $10.29303 /$ jrpb.v8i2.185

ISSN 2301-8119, e-ISSN 2443-1354

Tersedia online di http://jrpb.unram.ac.id/

\title{
PENGEMBANGAN ALAT PENCETAK PIRING PELEPAH PINANG (Areca catechu L.) DENGAN MENGGUNAKAN METODE QUALITY FUNCTION DEPLOYMENT
}

\author{
Design of Molding Tool for Manufacturing of Disposable Plate from \\ the Areca Palm (Areca catechu L.) Sheath using Quality Function Deployment Method
}

\section{Sahrial Hafids*), Yernisa Yernisa}

Program Studi Teknologi Industri Pertanian, Universitas Jambi

Kampus UNJA Pondok Meja, Jl Tri Brata, Km. 11, Pondok Meja, Jambi 36364, Indonesia

\author{
Email $^{*}$ : sahrial@unja.ac.id
}

Diterima: Juli 2020

Disetujui: September 2020

\begin{abstract}
Increasing awareness of the environmental impacts associated with the production and use of plastic plates gave rise to the idea of producing environmentally friendly plates from natural materials, such as the areca palm (Areca catechu L.) sheath. A molding tool is required to produce an areca sheath plate. This study aimed to improve the quality of the molding tool using the QFD Method. This method consists of four phases, i.e.: (1) Product Planning, (2) Part Development, (3) Process Planning, and (4) Production Planning. Based on the result of customer's requirements analysis, a list of the five priority of customer need had been generated, i.e.: (1) not tiring, (2) not rusty mold, (3) compact, sturdy and stable chassis, (4) ergonomic, and (5) replaceable mold. Five quality characteristics were determined to meet the five customer needs, i.e.: (1) automatic press, (2) ergonomic chassis, (3) not rusty material of mold, (4) rigid and strength material of chassis, and (5) minimalized dimension of mold. Therefore, it could be concluded that by using the four phases of the QFD Method, the areca plate mold tool that meets customer needs was successfully developed.
\end{abstract}

Keywords: molding tool; design; QFD Method; areca sheath plate

\begin{abstract}
ABSTRAK
Peningkatan kesadaran akan dampak lingkungan yang terkait dengan produksi dan penggunaan piring plastik memunculkan gagasan untuk memproduksi piring ramah lingkungan dari bahan alami, seperti pelepah pinang (Areca catechu L.). Untuk membuat piring dari pelepah pinang dibutuhkan alat pencetak. Penelitian ini bertujuan untuk meningkatkan kualitas alat pencetak dengan menggunakan Metode QFD. Metode ini terdiri dari empat tahapan, yaitu: (1) Perencanaan Produk, (2) Perencanaan Teknik, (3) Perencanaan Proses, dan (4) Perencanaan Produksi. Berdasarkan hasil analisis kebutuhan pelanggan dihasilkan daftar lima prioritas kebutuhan pelanggan, yaitu: (1) tidak melelahkan, (2) tidak berkarat, (3) rangka kompak, kokoh dan stabil, (4) ergonomis, dan (5) cetakan yang dapat diganti. Terdapat lima karakteristik kualitas untuk memenuhi lima kebutuhan pelanggan, yaitu: (1) pengepres otomatis, (2) sasis
\end{abstract}


ergonomis, (3) bahan cetakan tidak berkarat, (4) sasis kaku dan kuat, dan (5) desain minimalis. Oleh karena itu, dapat disimpulkan bahwa dengan menggunakan keempat fase Metode QFD alat pencetak piring dari pelepah pinang yang memenuhi kebutuhan pelanggan telah berhasil dikembangkan.

Kata kunci: alat pencetak; desain; Metode QFD; piring pelepah pinang

\section{PENDAHULUAN}

\section{Latar Belakang}

Meningkatnya kesadaran terhadap dampak lingkungan dari penggunaan piring plastik memunculkan ide untuk memproduksi piring ramah lingkungan dari pelepah pinang (Areca catechu L.). India adalah negara yang pertama kali mengembangkan piring pelepah pinang. Hal ini sejalan dengan posisi India sebagai produsen pinang terbesar di dunia (Patidar, 2015); Anonim, 2019). Selanjutnya, piring dari pelepah pinang dikembangkan di Malaysia, dan kemudian diikuti oleh Indonesia.

Saat ini, setidaknya terdapat empat produsen piring pelepah pinang di Indonesia. Dua produsen menggunakan alat pencetak piring (plate molding tool) yang diimpor dari India, dua lainnya memproduksi alat pencetak piring secara mandiri. Kedua jenis alat tersebut, baik impor ataupun produksi sendiri, bekerja dengan prinsip pencetakan (molding) pada suhu dan tekanan tinggi, yaitu pada kisaran suhu $110-170^{\circ} \mathrm{C}$ dan tekanan $500-800 \mathrm{kPa}$ dengan lama pencetakan 60-90 detik (Yernisa, 2018).

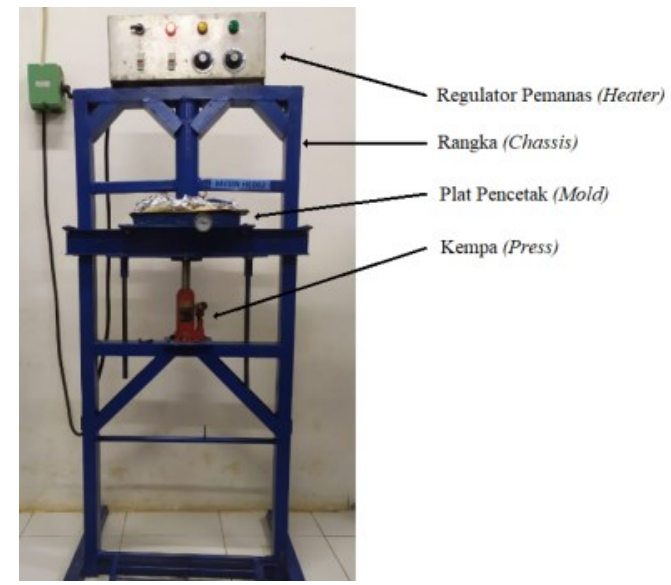

Gambar 1. Alat Plate Mold (Yernisa, 2018)
Terdapat tiga komponen utama pada alat plate molding (Gambar 1), yaitu: (1) mold (cetakan) yang berfungsi membentuk piringdari pelepah pinang, (2) heater atau pemanas mold, dan (3) press (kempa) untuk pressing pelepah di antara kedua permukaan mould.

Penelitian ini melakukan kajian pengembangan alat plate mold dengan menggunakan Metode Quality Function Deployment (QFD). QFD adalah metode untuk merancang produk sesuai dengan kebutuhan (need) pelanggan (Warwick Manufacturing Group, 2018). Produk yang baik adalah produk yang sesuai dengan kebutuhan pelanggan. Hal ini karena QFD dapat mengintegrasikan kebutuhan pelanggan ke dalam setiap aspek perancangan. Pada penelitian ini, pelanggan dari alat plate mould yang dikembangkan, terdiri dari: (1) produsen piring pelepah pinang, (2) petani pinang, dan (3) manajer Badan Usaha Milik Desa (BUMDes).

Kebutuhan dari pelanggan menjadi prioritas pengembangan alat plate mold. Pengembangan fokus pada komponen mold, heater, dan press. Di samping itu, dilakukan juga kajian pengembangan untuk komponen chassis agar alat yang dihasilkan menjadi lebih ergonomis.

\section{Tujuan}

Tujuan penelitian ini adalah untuk mengembangkan alat pencetak piring dari pelepah pinang (Areca catechu L.) dengan menggunakan Metode QFD. 


\section{METODE PENELITIAN}

\section{Obyek dan Subyek Penelitian}

Penelitian dilakukan di Laboratorium Komputer dan Instrumentasi, Jurusan Teknologi Industri Pertanian, Universitas Jambi. Obyek penelitian adalah alat plate molding. Penelitian difokuskan pada pengembangan komponen mold, heater, press, dan chassis. Adapun subyek untuk pengisian kuesioner adalah dua belas orang responden yang terdiri dari masing-masing empat orang produsen piring pelepah pinang, petani pinang, dan manajer BUMDes di Kabupaten Tanjung Jabung Barat dan Kabupaten Tanjung Jabung Timur, Provinsi Jambi.

\section{Metode}

Pengembangan rancangan alat plate mold menggunakan Metode QFD. Metode ini terdiri dari empat fase pengembangan (Cohen, 1995; Patro, 2013) sebagai berikut: 1. Perencanaan Produk. Fase ini fokus pada upaya menterjemahkan kebutuh-an pelanggan (customer requirement) menjadi kebutuhan teknis dan spesifikasi desain (technical descriptors). Hasil dari fase ini adalah diagram House of Quality (HoQ).

2. Perancangan Produk. Fase ini menjabarkan technical descriptors menjadi karakteristik part.
3. Perencanaan Proses. Fase ini menjabarkan karakteristik part menjadi key process.

4. Perencanaan Produksi. Fase ini mendefinisikan production requirements untuk proses pabrikasi.

\section{HASIL DAN PEMBAHASAN}

Dari hasil survei pada pelanggan diperoleh 15 kebutuhan (customer requirements) sebagaimana disajikan pada Tabel 1.

Tabel 1. Kebutuhan Pelanggan

\begin{tabular}{|c|c|c|}
\hline \multicolumn{3}{|c|}{ Kebutuhan } \\
\hline Primer & Sekunder & Tersier \\
\hline \multirow[t]{5}{*}{ Mold } & Performance & panas stabil \&merata \\
\hline & Feature & replacement mudah \\
\hline & Reliability & bentuk mold stabil \\
\hline & Durability & tidak mudah berkarat \\
\hline & Serviceability & mudah dibersihkan \\
\hline \multirow[t]{4}{*}{ Heater } & Performance & panas stabil \& merata \\
\hline & Feature & $\begin{array}{l}\text { suhu dapat diatur dan } \\
\text { aman }\end{array}$ \\
\hline & Reliability & $\begin{array}{l}\text { sumber energi mudah } \\
\text { diperoleh dan murah }\end{array}$ \\
\hline & Durability & peralatan awet \\
\hline \multirow[t]{3}{*}{ Press } & Performance & gaya tekan kuat \\
\hline & Durability & tidak mudah rusak \\
\hline & Serviceability & tidak melelahkan \\
\hline \multirow[t]{3}{*}{ Chassis } & Performance & kompak, kokoh, stabil \\
\hline & Serviceability & ergonomis \\
\hline & Aesthetics & tampilan menarik \\
\hline
\end{tabular}




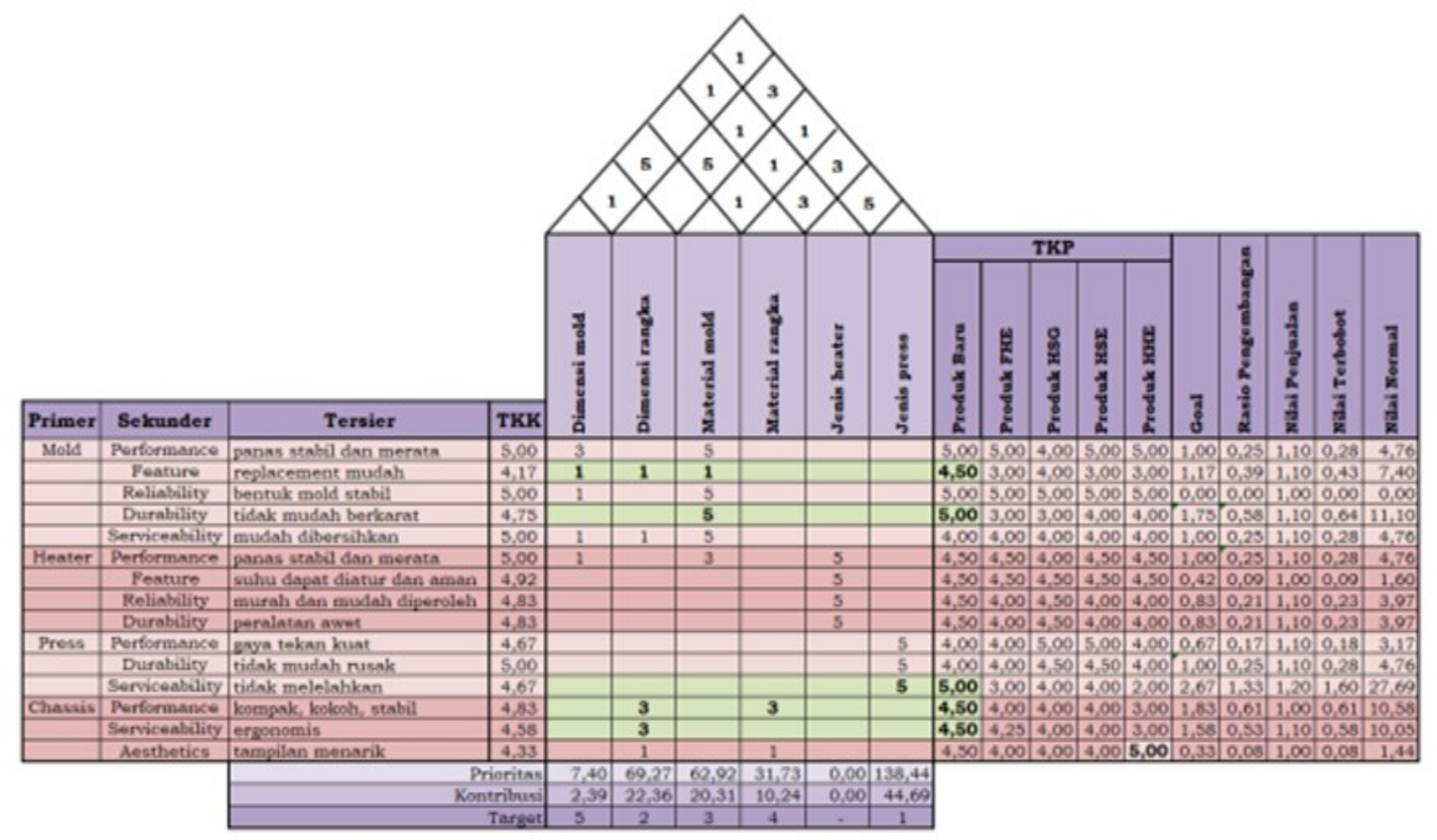

Gambar 2. House of Quality (HoQ)

Berdasarkan data kebutuhan pelanggan dibuat HoQ, Part Development, Process Planning, dan Production Planning sebagai berikut:

\section{House of Quality (HoQ)}

Diagram HoQ menghubungkan kebutuhan pelanggan (customer requirements) dengan kebutuhan teknis (technical descriptors) sebagaimana dapat dilihat pada Gambar 2. Berdasarkan hasil analisis terhadap kompetitor (Gambar 2) diketahui, terdapat lima kebutuhan pelanggan yang menjadi prioritas untuk dipenuhi. Pada Tabel 2 berikut disajikan daftar kelima prioritas tersebut beserta nilai normalnya.

Tabel 2. Prioritas Kebutuhan Pelanggan

\begin{tabular}{clc}
\hline \multicolumn{3}{c}{ Kebutuhan Pelanggan } \\
\hline \multirow{2}{*}{ Prioritas } & \multicolumn{1}{c}{ Kebutuhan } & $\begin{array}{c}\text { Nilai } \\
\text { Normal }\end{array}$ \\
\hline 1 & Tidak melelahkan & 27,69 \\
2 & Cetakan tidak berkarat & 11,10 \\
3 & Kompak, kokoh, dan stabil & 10,58 \\
4 & Ergonomis & 10,05 \\
5 & Cetakan mudah diganti & 7,40 \\
\hline
\end{tabular}

Selanjutnya berdasarkan prioritas kebutuhan pelanggan, dijabarkan kebutuhan teknis perancangan. Terdapat lima kebutuhan teknis untuk perancangan alat pencetak piring pelepah pinang. Tabel 3 menyajikan deskriptor kebutuhan teknis dan nilai kontribusi rancangan terhadap pemenuhan kebutuhan pelanggan yang diurut berdasarkan target prioritas.

Tabel 3. Kebutuhan Teknis

\begin{tabular}{ccl}
\hline & \multicolumn{2}{c}{ Kebutuhan Teknis } \\
\hline Target & Kontribusi & \multicolumn{1}{c}{ Deskriptor } \\
\hline 1 & 44,69 & Jenis kempa \\
2 & 22,36 & Dimensi rangka \\
3 & 20,31 & Material cetakan \\
4 & 10,24 & Material rangka \\
5 & 2,39 & Dimensi cetakan \\
\hline
\end{tabular}

\section{Part Development}

Penyusunan matriks part development bertujuan untuk mengidentifikasi rancangan (design) yang mempengaruhi hasil akhir produk (Cohen, 1995; Maulida, 2013). Gambar 3 memperlihatkan karakteristik part yang dibutuhkan untuk rancangbangun alat pencetak. Terdapat lima karakteristik part dari produk yang dikembangkan sebagai berikut: 
a. Jenis Kempa yang dibutuhkan adalah kempa otomatis, sehingga dapat mengurangi tingkat kelelahan pekerja, namun kempa tersebut juga harus mempunyai daya penekanan minimal $500 \mathrm{kPa}$.

b. Dimensi Rangka harus ergonomis. Untuk itu, desain rangka mengikuti dimensi antropometrik orang Indonesia dengan ukuran tinggi bahu rata-rata $126,79 \mathrm{~cm}$ (PEI [Perhimpunan Ergonomi Indonesia], 2020). Dimensi ini harus mampu menopang struktur alat yang kompak, kokoh, dan stabil.

c. Material Pencetak diharapkan tidak mudah berkarat, serta dapat diganti dengan mudah. Selain itu, juga diinginkan material pencetak yang mudah dibersihkan, memiliki daya hantar panas yang baik, dan tidak mudah memuai.

d. Material Rangka harus mampu menopang struktur alat yang kokoh dan kompak, serta mampu memberikan tampilan alat yang menarik.

e. Dimensi Pencetak diinginkan minimalis agar dapat mudah diganti, tetapi juga harus mampu memberikan panas secara merata dan stabil.

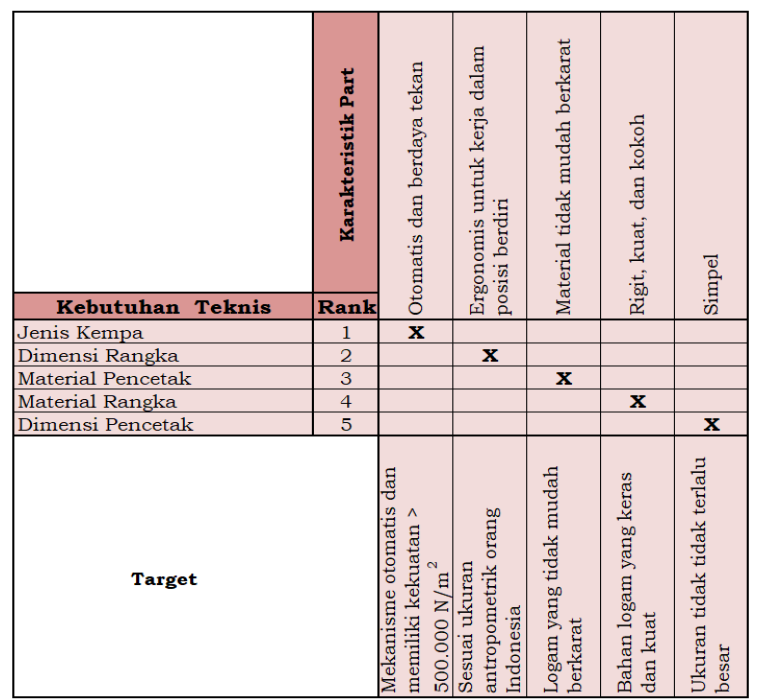

Gambar 3. Matriks Part Development

\section{Process Planning}

Matriks perencanaan proses (process planning) merupakan fase ketiga dalam pengembangan produk dengan metode QFD. Fase ini menganalisis proses pembuatan part dari matriks sebelumnya (Cohen, 1995) (Gambar 4).

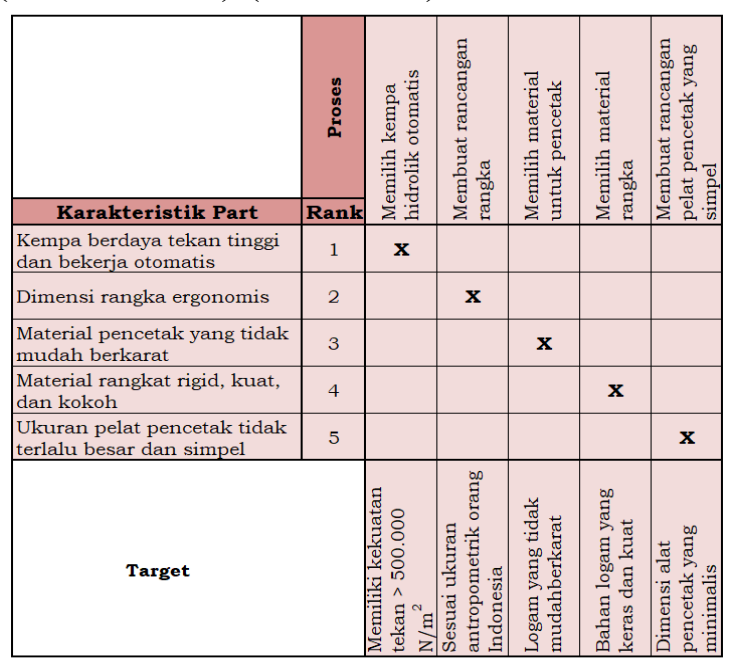

Gambar 4. Matriks Process Planning

Terdapat lima proses yang harus dilakukan untuk menghasilkan alat plate molding sesuai dengan kebutuhan pelanggan. Kelima proses tersebut adalah sebagai berikut:

a. Pemilihan Kempa. Untuk mendapatkan kempa otomatis berdaya tekan tinggi (di atas $500 \mathrm{kPa}$.) dilakukan dengan cara membuat (in house) atau membeli (out source). Keputusan beli atau buat tergantung pada integrasi vertikal proses pabrikasi (Nazaruddin, 2008). Karena produk baru yang pabrikasinya belum terintegrasi, maka pada penelitian ini pengadaan kempa dipilih dengan cara membelidengan pertimbangan teknis dan ekonomis (tekno-ekonomi) (Salengke, 2012).

b. Desain rangka mempertimbangkan aspek ergonomis berdasarkan ukuran antropometrik orang Indonesia yang memiliki tinggi bahu rata-rata $126,79 \mathrm{~cm}$ (Gambar 5).

c. Pemilihan Material Pencetak. Bahan atau material pencetak disyaratkan berupa logam yang tidak mudah berkarat, tetapi mudah dikonstruksi menjadi plat cetak (mold) berukuran minimalis. Selain itu, logam tersebut harus mempunyai sifat konduktivitas panas yang baik, tetapi memiliki koefisien muai yang rendah agar tidak terjadi perubahan bentuk cetakan pada suhu pencetakan di atas $100^{\circ} \mathrm{C}$. Terdapat dua 
pilihan yang sesuai dengan persyaratan tersebut, yaitu: aluminium atau besi. Tabel 4 menyajikan perbandingan karakteristik fisik kedua jenis logam tersebut.

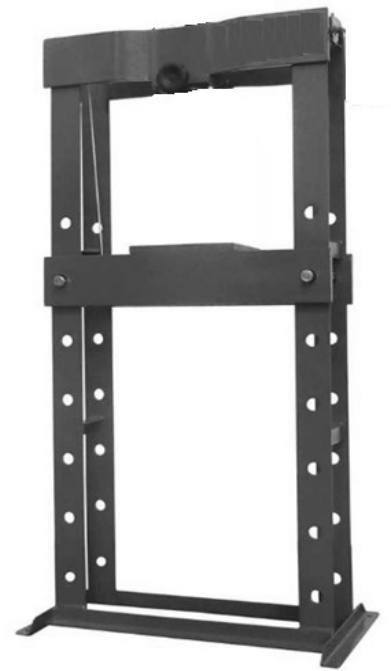

Gambar 5. Desain Rangka

Tabel 4. Pebandingan Karakteristik Fisik Logam Aluminium dan Besi

\begin{tabular}{lrr}
\hline \multicolumn{1}{c}{ Karakteristik } & \multicolumn{1}{c}{ Aluminium } & \multicolumn{1}{c}{ Besi } \\
\hline $\begin{array}{l}\text { Koefisien Muai Panjang } \\
\left(\text { per }{ }^{\circ} \mathrm{C}\right)\end{array}$ & 0,000026 & 0,000012 \\
$\begin{array}{l}\text { Konduktivitas Thermal } \\
\left(\mathrm{J} / \mathrm{s} . \mathrm{m} .{ }^{\circ} \mathrm{C}\right)\end{array}$ & 200 & 46 \\
$\begin{array}{l}\text { Panas Jenis }\left(\mathrm{J} / \mathrm{kg} .{ }^{\circ} \mathrm{C}\right) \\
\text { Massa Jenis }\left(\mathrm{kg} / \mathrm{m}^{3}\right)\end{array}$ & 900 & 450 \\
\hline
\end{tabular}

Dengan asumsi kenaikan suhu $100^{\circ} \mathrm{C}$ dan ukuran minimalis plat cetakan 30 $\mathrm{cm} \times 30 \mathrm{~cm} \times 4 \mathrm{~cm}$, laju konduksi $(\mathrm{J} / \mathrm{s})$, pemuaian (\%), dan jumlah kalor (J) untuk pemanasan alumnium dan besi dapat dilihat pada Tabel 5.

Tabel 5. Perbandingan karakteristik plat cetak aluminium dan besi

\begin{tabular}{lrr}
\hline \multicolumn{1}{c}{ Karakteristik } & Aluminium & \multicolumn{1}{c}{ Besi } \\
\hline Volume $\left(\mathrm{m}^{3}\right)$ & 0,036 & 0,036 \\
Berat $(\mathrm{kg})$ & 9,72 & 28,44 \\
Laju konduksi $(\mathrm{J} / \mathrm{s})$ & 6.000 & 1.380 \\
Pemuaian $(\%)$ & $1,75 \times 10^{-10}$ & $1,73 \times 10^{-11}$ \\
Jumlah kalor $(\mathrm{J})$ & 874.800 & 1.279 .800 \\
\hline
\end{tabular}

Dari data pada Tabel 5 diketahui, bahwa pemanasan dan penyebaran panas lebih mudah terjadi pada aluminium dibandingkan dengan besi. Akan tetapi, aluminium memuai lebih besar dibandingan dengan besi, namun pada suhu operasional $\left(110-170^{\circ} \mathrm{C}\right)$, pemuaian aluminium dan besi relatif kecil, sehingga pemilihan logam plat cetak didasarkan pada laju pemanasan dan penyebaran panas. Untuk alasan tersebut, aluminium dipandang lebih baik daripada besi.

d. Pemilihan Material Rangka. Bahan atau material rangka disyaratkan harus rigid, kuat, dan kokoh. Selain itu, material rangka harus aman pada suhu operasional di atas $100^{\circ} \mathrm{C}$. Untuk alasan tersebut, maka material rangka haruslah logam, dalam hal ini material rangka yang dipilih adalah besi.

e. Desain Plat Cetakan dipersyaratkan simpel atau minimalis agar mudah dilakukan replacement plat cetakan. Ukuran dimensi plat cetak didasarkan pada ukuran piring pelepah pinang yang akan dibuat. Berdasarkan data dari produsen piring pelepah pinang, diketahui bahwa ukuran maksimal piring dari pelepah pinang adalah $30 \mathrm{~cm}$. Dengan demikian, ukuran luas maksimal plat cetak adalah $30 \mathrm{~cm} \times 30 \mathrm{~cm}$, dengan ketebalan 3 sampai $4 \mathrm{~cm}$ (Gambar $6)$.

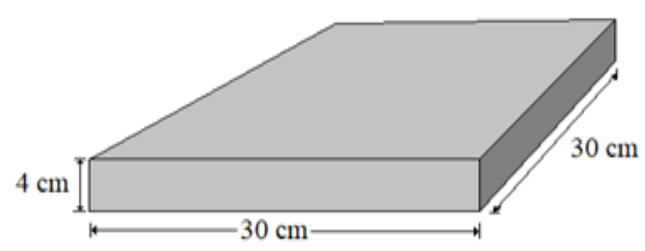

Gambar 6. Dimensi Plat Cetakan

\section{Production Planning}

Matriks perencanaan produksi (production planning) merupakan fase terakhir atau keempat dari Metode QFD seperti Gambar 7. 


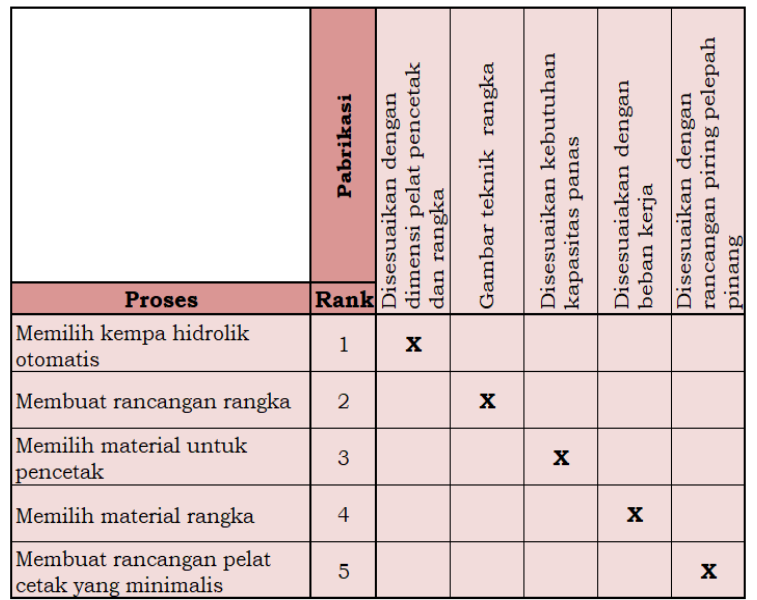

Gambar 7. Matriks Production Planning

Pada fase ini disusun rencana produksi (pabrikasi) untuk menghasilkan produk sesuai dengan keinginan pelanggan (Cohen, 1995).

Rencana produksi alat pencetak piring pelepah pinang adalah sebagai berikut:

a. Melakukan pemesanan dan pembelian kempa hidrolik sesuai dengan persyaratan teknis yang sudah ditentukan pada fase sebelumnya.

b. Membuat rangka (chassis) dengan bentuk dan dimensi yang sesuai dengan rancangan teknis.

c. Melakukan pemesanan dan pembelian material aluminium sebagai bahan pencetak (mold).

d. Melakukan pemesanan dan pembelian material rangka (chassis), selanjutnya mengkonstruksi rangka sesuai dengan desain dan dimensi yang sudah dihasilkan pada fase sebelumnya.

e. Membuat plat pencetak (mold) yang sesuai dengan desain piring yang akan dicetak.

Hasil akhir dari perancangan alat dengan menggunakan Metode QFD ini adalah alat pencetak piring (plate mold tool) dari pelepah pinang (Gambar 8). Alat ini memiliki tinggi $210 \mathrm{~cm}$ dan lebar $120 \mathrm{~cm}$. Plat pencetak berada pada ketinggian 130 $\mathrm{cm}$. Kempa hidrolik berada pada posisi atas yang berfungsi menekan plat dinamis, sedangkan plat statis berada pada bagian bawah.

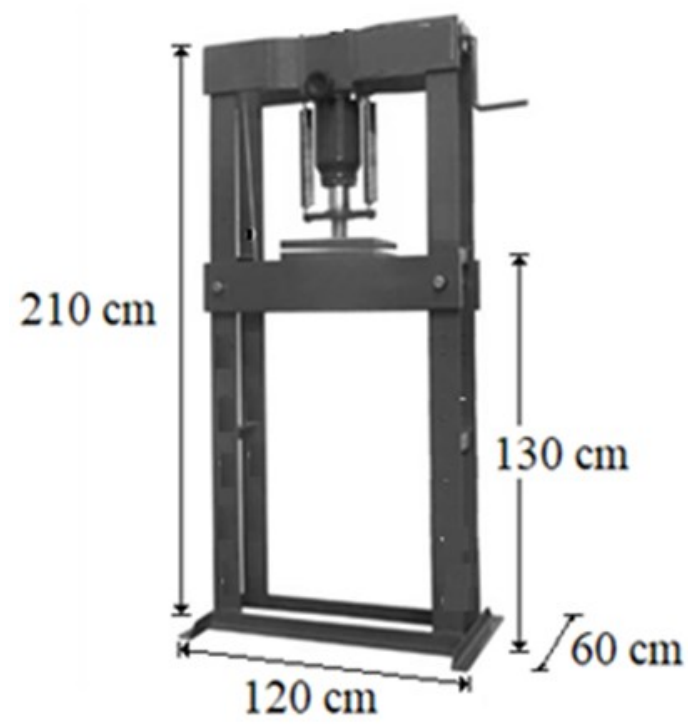

Gambar 8. Alat Pencetak Piring Pelepah Pinang

Dibandingkan dengan peralatan sebelumnya (Gambar 1), pengembangan terjadi pada tiga dari empat komponen alat yang dikaji, yaitu: pencetak (mold), kempa (press), dan rangka (chassis). Sedangkan untuk komponen pemanas (heater), pelanggan tidak secara spesifik menyatakan kebutuhannya.

Untuk komponen plat pencetak, dilakukan penggantian material dari besi menjadi aluminium. Untuk komponen kempa, dilakukan penggantian kempa dari kempa hidrolik manual menjadi kempa hidrolik otomatis. Penggantian ini bertujuan untuk mengurangi beban kerja.

Pada komponen rangka, perubahan dilakukan pada penempatan kempa dari semula berada di posisi bawah dipindah ke posisi atas. Perubahan posisi kempa ini memungkinkan untuk melakukan penggantian jenispemanas (heater) dari sebelumnya menggunakan energi listrik dapat diganti dengan menggunakan bahan bakar LPG.

Penggantian jenis alat pemanasan dengan menggunakan bakar gas LPG memungkin alat pencetak piring dari pelepah pinang ini dioperasikan di perkebunan pinang yang jauh dari sumber energi listrik. 


\section{KESIMPULAN DAN SARAN}

\section{Kesimpulan}

Penelitian pengembangan alat dengan menggunakan Metode QFD ini telah berhasil menghasilkan rancangan alat pencetak piring dari pelepah pinang dengan kualitas yang lebih baik daripada alat sebelumnya. Perubahan dilakukan pada komponen kempa, pencetak, dan rangka. Adapun untuk komponen alat pemanas, pelanggan tidak menyatakan secara spesifik kebutuhannya, namun hasil rancangan ini memungkinan untuk mengganti penggunaan pemanas dengan sumber energi listrik menjadi pemanas dengan bahan bakar LPG. Saran

Dirasa perlu untuk dilakukan penelitian lanjutan pembuatan alat pencetak piring pelepah pinang dengan menggunakan hasil rancangan dari penelitian ini.

\section{UCAPAN TERIMA KASIH}

Penulis mengucapkan terima kasih kepada Lembaga Penelitian dan Pengabdian kepada Masyarakat (LP2M) Universitas Jambi (UNJA) atas bantuan dana untuk penelitian ini.

\section{DAFTAR REFERENSI}

Anonim. (2019). Areca nut production in Asia Pacific 2017. https://www. statista.com/statistics/657902/asiapacific-areca-nut-production-bycountry/

Cohen, L. (1995). Quality function deployment: how to make QFD work for you.

Maulida, R. (2013). Pengembangan Produk Permen Susu Karamel untuk Meningkatkan Produktivitas Usaha Berdasarkan Kebutuhan Konsumen.
Jurnal Kalibrasi, 11(1): 1-9. https://sttgarut.ac.id/jurnal/index.php/k alibrasi/article/view/111.

Nazaruddin. (2008). Manajemen Teknologi. Graha Ilmu.

Patidar, K. A. (2015). Various terminologies associated with areca nut and tobacco chewing: A review. Journal of Oral \& Maxillofacial Pathology, 19(1): 69-76. http://www.jomfp.in/temp/JOralMaxill ofacPathol19169-

5159463_141954.pdf.

Patro, C. S. (2013). A Study on Implementation of Quality Functional Deployment Technique in Product design Stage. International Journal on Management Research and Reviews, 3(6): 2249-7196. http://ijmrr.com/view jouranal.aspx

PEI [Perhimpunan Ergonomi Indonesia]. (2020). Rekap Data Antropometri Indonesia. Antropometri Indonesia. https://antropometriindonesia.org/inde x.php/detail/artikel/4/10/data_antropo metri.

Salengke. (2012). Engineering Economy. Identitas Unhas.

Warwick Manufacturing Group. (2018). Product Excellence Using Six Sigma: Quality Function Deployment. School of Engineering University of Warwick.

Yernisa. (2018). Pemanfaatan Pelepah Pohon Pinang Menjadi Wadah Sekali Pakai (Disposible Plate) sebagai Alternatif Wadah Ramah Lingkungan. Prosiding Seminar Nasional Fakultas Pertanian Universitas Jambi. 